\title{
Subsídio e déficit habitacional no Programa MCMV
} Allowance and housing deficit in MCMV Program http://dx.doi.org/10.5007/2178-4582.2015v49n1p199

José Eduardo Baravelli

Faculdades Integradas Alcântara Machado, São Paulo/SP, Brasil

\begin{abstract}
$\mathrm{O}$ artigo recupera regulamentos de governo e estudos estatísticos sobre o programa Minha Casa Minha Vida para apontar o uso do conceito de déficit habitacional como legitimador institucional do programa de habitação do governo federal. Esta legitimação, por outro lado, esvazia de sentido político o subsídio habitacional para a provisão habitacional para famílias de baixa renda, ideal oriundo dos movimentos de moradia e que, uma vez transplantado para o centro do programa Minha Casa Minha Vida, se limita a dar suporte a uma política de desenvolvimento econômico da construção habitacional brasileira.
\end{abstract}

Palavras-chave: Habitação social - Programa Minha Casa Minha Vida - Déficit habitacional - Subsídio habitacional.
The article recovers government regulations and statistical studies on the Minha Casa Minha Vida Program to point the use of the concept of housing deficit as institutional legitimizing the federal housing program. This legitimacy, on the other hand, empty of political direction the housing subsidy for housing provision for low-income families, ideal coming from the housing movements and that, once transplanted into the center of the Minha Casa Minha Vida program is limited to give support an economic development policy of the Brazilian housing construction.

Keywords: Social housing - Minha Casa Minha Vida Program - Housing déficit - Housing subsidy.

\section{Introdução: um subsídio à urbanização de expansão horizontal}

Lançado em 2009, o programa federal Minha Casa Minha Vida se tornou o mais efetivo programa habitacional brasileiro desde a extinção do BNH, em 1986. Nesse intervalo, apenas a autoconstrução da moradia (com seus diversos graus de precariedade legal e urbana) conseguiu produzir habitação para famílias de baixa renda numa quantidade capaz de alterar a paisagem das periferias brasileiras. Em 2015, na iminência de acrescentar 3,75 milhões de moradias ao estoque habitacional do país, já se tornou lugar comum criticar o programa por submeter a produção da habitação popular a localizações urbanas sob domínio único de empresas construtoras privadas.

A crítica a esse domínio privado sobre um programa governamental, disseminada nos estudos urbanos brasileiros ${ }^{1}$, será realizada neste artigo

\footnotetext{
${ }^{1}$ Entre as críticas de primeira hora do programa MCMV, destacam-se Maricato (2009), Bonduki (2009) e Rolnik e Nakano (2009). Uma síntese delas pode ser encontrada em Cardoso (2013).
} 
por um ângulo mais preciso, focado na operação que está no centro do programa MCMV: o subsídio habitacional com fundos públicos da habitação para famílias de baixa renda. Esse subsídio, que é uma reivindicação histórica dos movimentos de moradia no Brasil, é apropriado antes pelas empresas construtoras do que pelas famílias cadastradas como beneficiadas pelo programa. Nesse processo, a própria noção de "déficit habitacional" passa a legitimar um subsídio que, se é efetivo para capitalizar a construção habitacional brasileira, é também inócuo para elevar o patamar quantitativo da provisão habitacional para a população de baixa renda do país.

O quadro final é uma contradição interna ao Plano Nacional de Habitação (PlanHab). Formulado no início da presidência Lula em consonância com o movimento da Reforma Urbana, o PlanHab deveria orientar o próprio programa federal de habitação a partir da recusa de "um modelo de urbanização baseado na expansão horizontal e na ampliação permanente das fronteiras, na subutilização da infraestrutura e da urbanidade já instaladas e na mobilidade centrada na lógica do automóvel particular" (BRASIL, 2009, p. 40). Tal "urbanização de expansão horizontal” tem consequências conhecidas:

\begin{abstract}
De um lado, a cidade se expande avançando sobre as áreas rurais e os perímetros urbanos definidos em lei municipal, acomodando de forma arbitrária as áreas que já foram ocupadas e aquelas que serão ocupadas no futuro; de outro lado, os vazios urbanos e imóveis vagos permanecem ociosos por vários anos [...] Um círculo vicioso ocorre quando o preço da terra tem a maior incidência no custo final da habitação; o alto valor em áreas urbanas centrais gera a ocupação da periferia, espalhando a malha urbana, criando vazios e inviabiliza a cidade equipada para a população de baixa renda (BRASIL, 2009, p. 40-41) ${ }^{2}$
\end{abstract}

Pois o que o PlanHab recusa é o que o programa MCMV realiza. Esse é o passo inicial para explicar a atual organização do subsídio habitacional na produção da habitação social com fundos públicos federais. O passo seguinte é confrontar essa política de subsídio não apenas com os pressupostos do movimento da Reforma Urbana, mas com os resultados que provoca sobre sua principal legitimação: o déficit habitacional brasileiro. O confronto entre

\footnotetext{
${ }^{2} \mathrm{Na}$ apresentação deste mesmo texto, a secretária nacional de habitação, Inês Magalhães, afirma que "o lançamento, em abril de 2009, do Programa Minha Casa Minha Vida - PMCMV colocou em curso um conjunto de diretrizes e ações previstas no PlanHab, representado pelos novos patamares de investimentos públicos no setor habitacional (R 34 bilhões até o final do PPA 2008-2011), com impacto direto na alavancagem do setor da construção civil” (BRASIL, 2009, p. 5). Justamente são esses números que fazem com que Nabil Bonduki, um dos principais redatores do PlanHab, seja menos condescendente: "O programa não adota o conjunto das estratégias que o PlanHab julgou indispensável para equacionar o problema habitacional, sobretudo nos eixos que não se relacionavam com os aspectos financeiros; em consequência, aborda-o de maneira incompleta, incorrendo em grandes riscos, ainda mais porque precisa gerar obras rapidamente sem que se tenha preparado para isso" (BONDUKI, 2009, p. 13).
} 
subsídio e déficit habitacional implica, dessa forma, o confronto entre documentos de natureza institucional, que regulam o programa MCMV por meio de leis, portarias e planos de governo, com estudos de base estatística que procuram medir seus efeitos na habitação social, particularmente as pesquisas do Instituto de Pesquisas Econômicas sobre dados PNAD.

\title{
As metas de um programa-plano
}

Um princípio da administração pública estipula que a implantação de um programa, o limiar de gestão antes da ação efetiva de governo, deve se prender a uma hierarquia de planejamento, em que o programa integra um plano de caráter setorial e, daí, uma política pública de longo prazo. É uma hierarquia pela qual toda atuação de órgão de governo, que é pontual e específica, se articulada a uma visão de Estado, que é ampla e abrangente.

O programa MCMV, no entanto, embaralha esse princípio por ser, desde sua instituição, um "programa-plano", na expressão dos economistas Cleandro Krause, Renato Balbim e Vicente Lima Neto; ele concentra tantos recursos e resultados que acaba por esvaziar, pela ponta final da ação de governo, seu próprio pressuposto de planejamento: o Plano Nacional de Habitação, marco legal para onde confluem um arranjo institucional e orçamentário composto, respectivamente, pelo "Sistema Nacional" e pelo "Fundo Nacional" que suportariam a "Habitação de Interesse Social":

\begin{abstract}
Desde seu lançamento, o MCMV passou a encabeçar a atuação do governo federal na provisão habitacional, promovendo, em sua esteira, mudanças no próprio marco do Sistema Nacional de Habitação de Interesse Social (SNHIS). Uma das mudanças mais importantes foi que o Fundo Nacional de Habitação de Interesse Social (FNHIS), o principal instrumento de efetivação do SNHIS com recursos do Orçamento Geral da União (OGU), praticamente deixou de apoiar a provisão pública de habitação de interesse social [...] o MCMV, que define uma estratégia de ação e apresenta os mecanismos para tanto, parece ter sido alçado à esfera de política de provisão habitacional. (KRAUSE; BALBIM; LIMA NETO, 2013, p. 7-8) ${ }^{3}$
\end{abstract}

Já o programa MCMV é impulsionado por uma única meta: a construção de novas unidades habitacionais, na forma de conjuntos condominiais implantados em glebas vazias ou que tenham edificações demolidas já na etapa de limpeza do terreno. Quando foi lançado em março de 2009 através da Medida

\footnotetext{
3 "Mesmo sendo formalmente um único programa, com espectro de atendimento bastante amplo, [...] o programa MCMV na prática pode ser visto como uma política com diferentes estratégias de atendimento conforme a faixa de renda da população" (FERREIRA, 2012, p. 40-41).
} 
Provisória 459, era esta "meta física" que estava no centro de sua divulgação pública, no número exato de 1 milhão de moradias".

Em dezembro de 2010, outra Medida Provisória (de número 514), preparada pela equipe de transição da recém-eleita Presidente da República Dilma Rousseff, fazia inúmeras alterações na operação do programa, que passou a receber a designação "MCMV 2". No entanto, ao ser promulgada como Lei Federal 12.424 em julho de 2011, a modificação enfatizada foi a duplicação da meta física para dois milhões de novas unidades habitacionais ${ }^{5}$.

Imagem 1: Material publicitário da fase 1 e fase 2 do programa MCMV

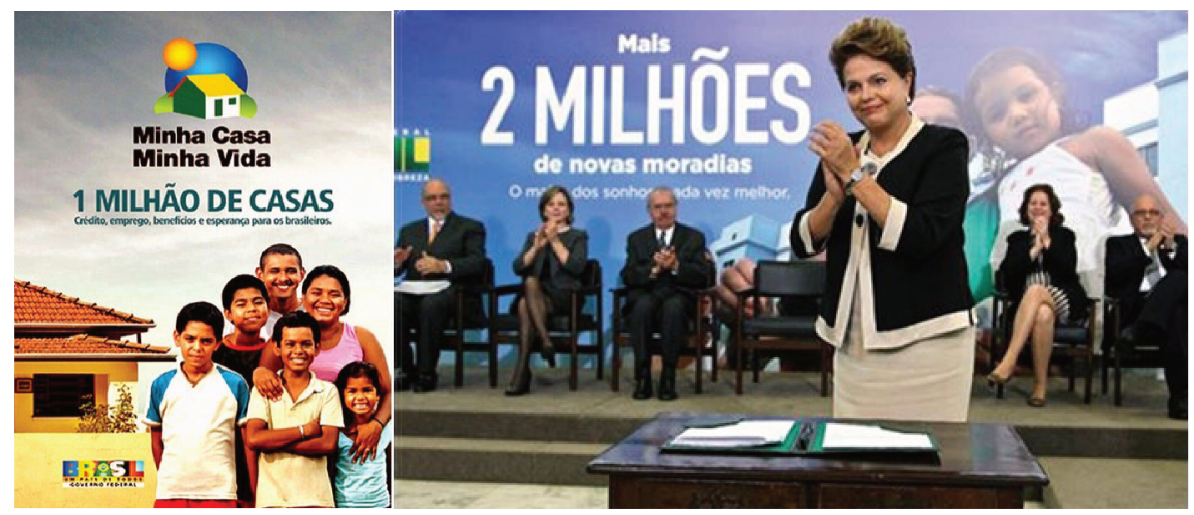

À esquerda, capa da primeira cartilha do programa MCMV, editada pela Casa Civil e distribuída pela CEF; à direita, foto oficial da promulgação do MCMV 2 (blog.planalto.gov.br). Em ambas imagens, a ênfase na "meta física" de produção é evidente.

A transição entre as duas etapas do programa MCMV é um ponto de observação natural para avaliar a pertinência dessas metas milionárias, pois conta com os resultados oficiais da primeira prestação de contas pública do programa, datada de 31 de dezembro de 2009 , último dia em que funcionou como "marca de gestão" da presidência Lula. Essa prestação de contas subdivide a meta segundo o aspecto socialmente mais progressivo do programa MCMV,

\footnotetext{
${ }^{4}$ A Medida Provisória foi convertida na Lei Federal 11.977 em 07 de julho de 2009 . Num artigo publicado na mesma época, o coordenador técnico da equipe que elaborou o PlanHab, Nabil Bonduki, classificou tal exatidão numérica como "uma meta cabalística" (BONDUKI, 2009, p. 8).

${ }^{5}$ Mesmo assim, $\mathrm{o}$ Artigo $1^{\circ}$ de ambas as leis federais inclui entre as finalidades do programa MCMV a "requalificação de imóveis urbanos", o que mostra a insuficiência da análise de uma ação de governo apenas por leis e regulamentos. Em abril de 2012, Dilma Rousseff anunciou a elevação de meta do programa em mais 400 mil unidades habitacionais destinadas a pequenos municipios, cedendo da seguinte forma a uma exigência do clientelismo difuso praticado por sua base de sustentação no legislativo federal: "a primeira condição é o déficit habitacional, por esse critério a concentração seria nos grandes municípios. Mas leva em conta também a desigualdade social, a existência de pobreza nos municípios e nas regiões. A combinação desses dois critérios permitiu que a gente pudesse enfrentar com muita determinação a concentração de pobreza em algumas regiốes" (DAMÉ, 2012, p. 22).
} 
que é uma clara diferenciação de faixas de subsídios e benefícios por faixas de renda familiar mensal. Medidas em salários mínimos ( $\mathrm{sm}$ ), as faixas de renda da primeira etapa do programa eram 0 a $3 \mathrm{sm}, 3$ a $6 \mathrm{sm}$ e 6 a $10 \mathrm{sm}$. Mesmo os críticos mais atentos a tamanha amplitude de renda familiar não deixaram de perceber que, de forma inédita, estava aberta a possibilidade para subsidiar, a partir de verbas orçamentárias da União, moradias para famílias de baixa renda ou mesmo para famílias sem renda alguma:

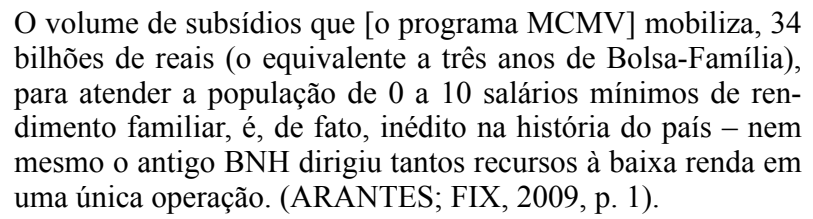

$\mathrm{Na}$ primeira prestação de contas do programa MCMV, estavam contratadas pelo operador financeiro do programa, a CEF, até dezembro de 2010, a construção de 1.005.128 unidades habitacionais. Na Tabela 1, essa soma aparece dividida entre as três faixas de renda estipuladas pela primeira etapa do programa MCMV, bem como as modalidades de contratação:

Tabela 1: MCMV 1 - Contratação por faixa de renda e modalidade

\begin{tabular}{|c|c|c|c|c|}
\hline $\begin{array}{c}\text { Renda } \\
\text { (sm) }\end{array}$ & $\begin{array}{l}\text { Meta } \\
\text { (UH) }\end{array}$ & Modalidade de contratação & $\begin{array}{l}\text { Contratos } \\
\text { (UH) }\end{array}$ & $\%$ \\
\hline \multirow{6}{*}{0 a 3} & \multirow{6}{*}{400.000} & Repasse para construtoras (FAR) & 404.407 & 40,23 \\
\hline & & Subsídio pelo FGTS & 88.580 & 8,81 \\
\hline & & $\begin{array}{l}\text { Oferta pública em cidades até } \\
50 \mathrm{mil} \mathrm{hab.}\end{array}$ & 63.772 & 6,34 \\
\hline & & $\begin{array}{c}\text { Repasse para entidades organiza- } \\
\text { doras (FDS) }\end{array}$ & 9.395 & 0,93 \\
\hline & & $\begin{array}{c}\text { Repasse para habitação rural } \\
\text { (PNHR) }\end{array}$ & 5.167 & 0,51 \\
\hline & & Subtotal & 571.321 & 56,84 \\
\hline 3 a 6 & 400.000 & Financiamento pelo FGTS & 284.772 & 28,33 \\
\hline 6 a 10 & 200.000 & Financiamento pelo FGTS & 149.035 & 14,83 \\
\hline & & Total & 1.005 .128 & 100,00 \\
\hline
\end{tabular}

Fonte: elaboração própria a partir da Lei Federal 11.977 e Ministério das Cidades. 


\title{
O subsídio habitacional
}

As diversas escalas de subsídio oriundos de aportes do Orçamento Geral da União ao programa - que chegaram no triênio 2011-2013 a R\$ 176 bilhões - dão capacidade consumidora a uma população que, de outra forma, continuaria a ser uma demanda por habitação sem valor de mercado. André Singer trata a racionalidade dessa política como parte do "sonho rooseveltiano" do segundo mandato Lula (SINGER, 2012, p. 125), sonho para o qual Pedro Arantes e Mariana Fix dão uma interpretação focada na provisão habitacional nos seguintes termos:

\begin{abstract}
A história do subsídio habitacional no Brasil é conhecida pela constante captura da subvenção pelas classes médias e agentes privados da produção imobiliária, ao invés de atender, na escala necessária, os trabalhadores que mais precisam. Embora essa tendência deva novamente prevalecer, há que se considerar o interesse político e eleitoral do governo em atingir a base da pirâmide. Ao contrário do regime militar, no qual a sustentação era dada sobretudo pelas classes médias, o governo Lula precisa fazer chegar a casa a uma parcela do seu eleitorado. (ARANTES; FIX, 2009, p. 4)
\end{abstract}

$\mathrm{Na}$ forma final que o programa MCMV recebeu através da Lei Federal 12.424, os subsídios aparecem tanto nas dotações orçamentárias para o seu principal fundo, o FAR, quanto nas diversas disposições legais que concedem isenções fiscais e de custos de registro imobiliário, além dos novos dispositivos legais para regularização fundiária em terrenos a serem doados como contrapartidas municipais aos empreendimentos financiados pelo programa, principalmente através do "auto de demarcação urbanística".

A lei também cria um instrumento de segurança para os recursos onerosos, através do "Fundo Garantidor da Habitação Popular" (FGHab), que refinancia as prestações mensais de arrendamento em caso de inadimplência e confere segurança tanto para as operações financeiras da Caixa Econômica Federal quanto aos empréstimos subsidiados para construção de infraestrutura urbana previstos por parte do Banco Nacional de Desenvolvimento Social (BNDES).

\footnotetext{
${ }^{6}$ A "captura da subvenção" é característica dos programas habitacionais dos anos 1970-1980 financiados pelo BNH, como atesta uma análise da época: "O Banco Nacional da Habitação atuando essencialmente como um banco comercial, sem uma clara política de distribuição dos financiamentos pelo espectro social, permitiu distorções na alocação dos recursos, provocadas, sem dúvida, pela especulação imobiliária, que prefere as garantias oferecidas pela classe média às dificuldades e incertezas das classes de menor poder aquisitivo" (BRUNA, 1976, p. 109). Ermínia Maricato fez uma recuperação histórica e crítica sobre as tentativas dos movimentos sociais de moradia em dar um direcionamento democrático ao subsídio habitacional e os impasses institucionais a que chegou (MARICATO, 2011).
} 
Na ponta do consumo final da unidade habitacional, o subsídio mais impactante é o que incide para a faixa de renda familiar mais baixa do programa MCMV, que, até o fim da primeira presidência Dilma Rousseff, se manteve desvinculada dos aumentos do salário mínimo ao fixar um valor-teto de $\mathrm{R} \$$ 1.600, que recebe a denominação pouco descritiva de "Faixa 1". O quadro completo das faixas de renda e das correspondentes metas físicas e modalidades de contratação aparece na Tabela 2.

Tabela 2: MCMV 2 - Contratação por faixa de renda e modalidade

\begin{tabular}{|c|c|c|c|}
\hline $\begin{array}{l}\text { Faixa de } \\
\text { renda }\end{array}$ & Modalidade de contratação & $\begin{array}{l}\text { Meta física } \\
\text { (UH) }\end{array}$ & $\%$ \\
\hline \multirow{4}{*}{ Até $\mathrm{R} \$ 1.600$} & Repasse para construtoras (FAR) & 860.000 & 43 \\
\hline & Oferta pública em cidades até 50 mil hab. & 220.000 & 11 \\
\hline & $\begin{array}{l}\text { Repasse para entidades organizadoras } \\
\text { (FDS) }\end{array}$ & 60.000 & 3 \\
\hline & Repasse para habitação rural (PNHR) & 60.000 & 3 \\
\hline $\begin{array}{l}\mathrm{R} \$ 1,600 \text { a } \mathrm{R} \$ \\
\quad 3.275\end{array}$ & $\begin{array}{l}\text { Financiamento subvencionado pelo } \\
\text { FGTS }\end{array}$ & 600.000 & 30 \\
\hline \multirow[t]{2}{*}{$\begin{array}{c}\mathrm{R} \$ 3.275 \mathrm{a} \mathrm{R} \$ \\
5.000\end{array}$} & $\begin{array}{l}\text { Financiamento subvencionado pelo } \\
\text { FGTS }\end{array}$ & 200.000 & 10 \\
\hline & Total & 2 milhões & 100 \\
\hline
\end{tabular}

Fonte: elaboração própria a partir da Lei Federal 12.424/2011 e Resolução 702 do CGFGTS.

A maior meta parcial do programa MCMV em sua fase atual está concentrada no Fundo de Arrendamento Residencial (FAR): 43\% da meta total de dois milhões de moradias estabelecida em julho de 2011. Esse fundo financia exclusivamente projetos habitacionais para baixa renda elaborados e apresentados à CEF por empresas construtoras privadas?

São também empresas privadas que produzem os imóveis ofertados com juros subsidiados para as faixas de renda entre $\mathrm{R} \$ 1.600$ e $\mathrm{R} \$ 3.275$ ("Faixa 2") e entre R\$3.275 e R\$ 5.000 (“Faixa 3"), desta vez com recursos do quase cinquentenário Fundo de Garantia por Tempo de Serviço (FGTS) ${ }^{8}$.

\footnotetext{
${ }^{7}$ Além da oferta pública de recursos para pequenas cidades, aparece com pouca expressividade como modalidade de contratação para baixa renda em área urbana o repasse a empreendimentos organizados por movimentos de moradia, com recursos do Fundo de Desenvolvimento Social (FDS). O encolhimento desta forma socialmente mais progressista de provisão habitacional, indicativa de uma inflexão conservadora do Partido dos Trabalhadores, é tema de uma recente pesquisa de Evaniza Rodrigues (RODRIGUES, 2013).

${ }^{8}$ Faixas de renda atualizadas conforme Decreto Federal 7.825 de 15 de outubro de 2012 e Resolução 702 do Conselho Gestor do FGTS. O capítulo 8 analisa a interação entre a altamente subsidiada "Faixa 1", exclusiva da habitação de baixa renda, e as faixas de renda média "Faixa 2" e "Faixa 3", uma vez que as mesmas empresas construtoras gerenciam empreendimentos muito semelhantes entre estas modalidades do programa MCMV.
} 
O FAR é "um fundo público secundário e sem conselho ... mais maleável e desregulado, capaz de atender ao interesse do capital da construção" (ARANTES; FIX, 2009, p. 13). Herdado de um antigo programa habitacional operado pela CEF, seu estrito controle governamental se desdobra num controle tanto da produção do imóvel, pelo instrumento do repasse, quanto do seu consumo, pelo instrumento do arrendamento. Pelo repasse, a empresa construtora é remunerada unicamente por custos construtivos e recebe a última parcela apenas após a transferência de todo o empreendimento à CEF. Pelo arrendamento, a CEF prolonga a regulação de uso da edificação e de sua fração ideal pelos dez primeiros anos de ocupação do imóvel pela família moradora, prazo durante o qual o financiamento é considerado uma locação com opção de compra após quitação de todos os pagamentos. As 120 parcelas mensais de arrendamento, no entanto, são altamente subsidiadas. A Tabela 3 indica a porcentagem assumida pelo FAR para os limites de renda familiar superior e inferior da "Faixa 1" quando se considera o máximo valor de repasse da unidade habitacional na Região Metropolitana de São Paulo, que se manteve até meados de 2015 em R\$ 76 mil.

Tabela 3: MCMV 2 - Subsídio máximo e mínimo para Faixa 1 na RMSP

\begin{tabular}{c|c|c|c|c}
$\begin{array}{c}\text { Renda } \\
\text { familiar }\end{array}$ & $\begin{array}{c}\text { Prestação } \\
\text { mensal }\end{array}$ & $\mathbf{1 2 0}$ prestações & $\begin{array}{c}\text { Subsídio pelo } \\
\text { FAR }\end{array}$ & \% subsídio \\
\hline $\begin{array}{c}\text { Menor que } \mathrm{R} \$ \\
500,00\end{array}$ & $\mathrm{R} \$ 25,00$ & $\mathrm{R} \$ 3.000,00$ & $\mathrm{R} \$ 73.000,00$ & $96,05 \%$ \\
\hline $\mathrm{R} \$ 1.600,00$ & $\mathrm{R} \$ 80,00$ & $\mathrm{R} \$ 9.600,00$ & $\mathrm{R} \$ 66.400,00$ & $87,37 \%$
\end{tabular}

Fonte: Elaboração própria a partir da Portaria Interministerial 477 de 14 de Outubro de 2013

$\mathrm{Na}$ linguagem do agente financeiro do programa, a Caixa Econômica Federal, o MCMV concede às famílias da "Faixa 1" o "subsídio integral do valor da moradia", uma vez que autoriza o FAR "a absorver o saldo residual" de um plano de pagamentos com prestação mínima de R\$ 25 até o limite de $5 \%$ da renda familiar, por um prazo de 10 anos. Por dispensar qualquer investigação cadastral, não importa qual o grau de integração aos circuitos de crédito ou consumo no Brasil, uma família cadastrada pelo governo municipal se integra ao programa MCMV assim que possa assumir o simbólico pagamento mensal de $\mathrm{R} \$ 25$.

A porcentagem de subsídio, que oscila em torno de $90 \%$ do valor total da moradia, decorre tanto do baixo valor a ser despendido pelas famílias moradoras durante o arrendamento quanto do alto valor que o programa MCMV repassa à empresa construtora. $\mathrm{O}$ valor de $\mathrm{R} \$ 76.000$ na região metropolitana de São Paulo, vigente até meados de 2015, é o maior do Brasil e pode ainda 
obter um "Apoio Financeiro Complementar" do Fundo Paulista de Habitação de Interesse Social, no valor de R \$ 20 mil por unidade?.

A construção de um apartamento de padrão popular na RMSP, caso seja repassado à $\mathrm{CEF}$ pelo valor máximo de $\mathrm{R} \$ 96$ mil, teria um custo por unidade de área construída em torno de $\mathrm{R} \$ 2 \mathrm{mil} / \mathrm{m}^{2}$, quando o correspondente indicador de custo de construção CUB $/ \mathrm{m}^{2}$ (do projeto-padrão de Interesse Social) é $\mathrm{R} \$ 796,03 / \mathrm{m}^{2} \mathrm{em}$ abril de 2015 (sem desonerações). A diferença em torno de $\mathrm{R} \$ 1.200 / \mathrm{m}^{2}$ se torna então uma remuneração movediça para a compra do terreno e a bonificação da empresa construtora, que é difícil de ser comprovada através do orçamento do empreendimento.

\section{O déficit habitacional}

O cálculo de déficit habitacional brasileiro utilizado no programa MCMV segue a metodologia estabelecida pela Fundação João Pinheiro (FJP) na elaboração da "Pesquisa de Necessidades Habitacionais", pesquisa contratada pelo próprio Ministério das Cidades em apoio à elaboração do PlanHab (FJP, 2011). A metodologia parte de variáveis da Pesquisa Nacional por Amostra de Domicílios (PNAD) que permitem identificar como características dos "domicílios particulares permanentes" quatro fatores de déficit habitacional: despesa excessiva com aluguel, coabitação involuntária entre famílias, precariedade construtiva e adensamento excessivo dos dormitórios. Como a PNAD é realizada pelo Instituto Brasileiro de Geografia e Estatística em todos os anos não censitários, as variáveis selecionadas pela FJP puderam ser agrupadas numa série histórica entre 2007 e 2012 pela "Nota Técnica 5" do Instituto de Pesquisa Econômica. Essa série histórica (Tabela 4) fornece um panorama do total de domicílios e do déficit habitacional brasileiro tanto em meio urbano quanto em meio rural:

Tabela 4: PNAD - Domicílios e déficit habitacional no Brasil - 2007 a 2012

\begin{tabular}{l|c|c|c|c|c|c}
$\begin{array}{l}\text { Doms e } \\
\text { Déficit }\end{array}$ & $\mathbf{2 0 0 7}$ & $\mathbf{2 0 0 8}$ & $\mathbf{2 0 0 9}$ & $\mathbf{2 0 1 1}$ & $\mathbf{2 0 1 2}$ & Variação \\
\hline $\begin{array}{l}\text { Doms. } \\
\text { urbanos }\end{array}$ & 47.536 .349 & 49.097 .569 & 50.044 .074 & 53.219 .429 & 54.446 .869 & $14,54 \%$ \\
\hline $\begin{array}{l}\text { Déficit } \\
\text { urbano }\end{array}$ & 4.607 .176 & 4.278 .033 & 4.791 .825 & 4.548 .545 & 4.502 .572 & $-2,27 \%$ \\
$\begin{array}{l}\text { Doms. } \\
\text { rurais }\end{array}$ & 8.381 .689 & 8.605 .592 & 8.640 .529 & 8.250 .625 & 8.549 .663 & $2,00 \%$ \\
\hline
\end{tabular}

${ }^{9}$ O Fundo Paulista de Habitação de Interesse Social - FPHIS - foi instituído em janeiro de 2008 pela Lei Estadual 12.801. O seu conselho gestor aprovou a complementação de recursos do programa MCMV através da Deliberação Normativa 6 e 8 de 20 de março de 2012. 


\begin{tabular}{l|c|c|c|c|c|c}
\hline $\begin{array}{l}\text { Déficit } \\
\text { rural }\end{array}$ & 986.015 & 913.532 & 911.178 & 860.665 & 741.953 & $-24,75 \%$ \\
$\begin{array}{l}\text { Total } \\
\text { doms. }\end{array}$ & 55.918 .038 & 57.703 .161 & 58.684 .603 & 61.470 .054 & 62.996 .532 & $12,66 \%$ \\
\hline $\begin{array}{l}\text { Total } \\
\text { déficit }\end{array}$ & 5.593 .191 & 5.191 .565 & 5.703 .003 & 5.409 .210 & 5.244 .525 & $-6,23 \%$
\end{tabular}

Fonte: adaptado de Lima Neto, Furtado e Krause (2013, p. 4 e 6).

Vista de forma abrangente, a série histórica indica que o primeiro milhão de moradias do programa MCMV, contratado em 2009 e construído ao longo de 2010 e 2011, se incorporou ao crescimento do número de domicílios particulares permanentes no país - que foi de $12,66 \%$ entre 2007 e 2012 - sem ter um efeito que possa ser isolado na queda de $6,23 \%$ do déficit habitacional no mesmo período, queda que segue uma tendência observável antes de 2009.

A impressão de que a lenta queda do déficit habitacional tem um curso independente do programa MCMV se reforça quando os números agregados para meio rural e meio urbano mostram que ela se concentra no minoritário grupo de domicílios rurais, onde havia em 2012 um quarto a menos de domicílios com fatores de déficit habitacional do que em 2007. Nesse mesmo intervalo e no grupo largamente majoritário de domicílios urbanos, o déficit habitacional se reduziu muito menos: $2,27 \%$. Como se pode ver na Tabela 1 , a primeira etapa do programa MCMV teve um desempenho modesto fora das cidades, com apenas 5.167 moradias contratadas pelo subprograma de habitação rural ${ }^{10}$.

Mesmo o papel que o programa MCMV poderia ter na pequena queda do déficit habitacional nas cidades adquire um caráter problemático quando se observa como ele evoluiu pelas diferentes faixas de renda familiar.

Tomando os números absolutos levantados pela Fundação João Pinheiro com dados da PNAD de 2008 (FJP, 2011), fica clara a imensa concentração do déficit habitacional na faixa de renda familiar entre 0 e 3 salários mínimos, que em meio urbano era de 4.113.659 domicílios. Diante desse contingente, o programa MCMV contratou em sua primeira etapa a construção ou o financiamento de 571.321 novas unidades habitacionais para famílias com renda mensal entre 0 e 3 salários mínimos, o que representa $142,8 \%$ da sua meta física inicial, mas apenas $13,8 \%$ do déficit do ano anterior entre os domicílios

\footnotetext{
${ }^{10}$ Não é possível converter este confronto entre metas e amostras censitárias num juízo definitivo sobre o desempenho do programa MCMV, mas ao menos ele não cede ao gesto fácil de submergir a noção de déficit habitacional numa crítica em bloco da segregação urbana brasileira: "a noção de déficit habitacional como número a ser quantitativamente superado cai por terra na medida em que há no país um estoque de seis milhões de domicílios vagos. Essa estatística revela não só a má distribuição das moradias, em razão da atuação dos agentes do mercado privado, mas também o baixo poder aquisitivo dos pobres no acesso ao estoque habitacional adequado" (NASCIMENTO; TOSTES, 2011).
} 
de baixa renda. No entanto, as 433.807 unidades habitacionais contratadas na mesma etapa do programa MCMV para as faixas de renda entre 3 e 10 salários mínimos, embora representem $3 / 4$ da meta inicial, correspondem à quase a totalidade do déficit habitacional levantado pela FJP para essa ampla faixa de renda, estimado em 2008 em 448.565 domicílios. A disparidade entre meta e déficit que se verifica nos domicílios da população de baixa renda não existe, portanto, nos domicílios da população de renda mais elevada.

Assim, era de se esperar já no lançamento do programa MCMV que o déficit habitacional brasileiro, caso se reduzisse, se reduziria de forma desigual, apenas pelo atendimento dos extratos de maior renda. A série histórica 2007/2012 realizada pelo IPEA confirma essa expectativa ao distribuir os dados da PNAD por faixas de renda familiar. Essa distribuição é reproduzida na tabela 5, com destaque para a evolução do déficit habitacional entre domicílios de baixa renda:

Tabela 5: PNDA - Déficit habitacional por faixa de renda familiar - 2007/2012

\begin{tabular}{l|c|c|c|c|c} 
Renda familiar mensal & $\mathbf{2 0 0 7}$ & $\mathbf{2 0 0 8}$ & $\mathbf{2 0 0 9}$ & $\mathbf{2 0 1 1}$ & $\mathbf{2 0 1 2}$ \\
\hline Até 3 SM & $70,7 \%$ & $70,2 \%$ & $71,2 \%$ & $73,0 \%$ & $73,6 \%$ \\
\hline Entre 3 e 5 SM & $13,1 \%$ & $14,0 \%$ & $13,5 \%$ & $11,7 \%$ & $11,6 \%$ \\
\hline Entre 5 e 10 SM & $10,4 \%$ & $10,3 \%$ & $9,6 \%$ & $9,1 \%$ & $9,4 \%$ \\
\hline Acima de 10 SM & $4,1 \%$ & $3,9 \%$ & $3,8 \%$ & $3,2 \%$ & $2,9 \%$ \\
\hline Sem declaração de renda & $1,7 \%$ & $1,7 \%$ & $1,9 \%$ & $3,0 \%$ & $2,4 \%$
\end{tabular}

Fonte: Lima Neto, Furtado e Krause (2013, p. 5)

Os levantamentos estatísticos ainda deixam várias questões em aberto sobre os efeitos do programa MCMV na pequena diminuição do déficit habitacional total nas cidades brasileiras, pois permitem pensar que o programa, se não reduziu o déficit, evitou que ele se ampliasse. No entanto, uma questão já pode ser fechada: o programa MCMV tornou o déficit socialmente mais regressivo. A partir de uma inflexão em 2009, o déficit habitacional brasileiro tem participação cada vez maior de domicílios pobres e, como o cumprimento das metas físicas é significativo apenas para o déficit medido nas faixas de renda de 3 a 10 salários mínimos, é o programa MCMV que retira prioritariamente as faixas de renda média desse cálculo.

Uma confirmação indireta do empobrecimento do déficit habitacional brasileiro está em outra decomposição possível dessa quantificação, desta vez não por faixa de renda, mas por fator domiciliar de déficit. 
Dos quatro fatores cuja presença no levantamento PNAD é suficiente para indicar déficit habitacional, três deles têm distribuição variada entre meio rural e urbano: a coabitação (quando famílias ocupam apenas cômodos ou dividem de maneira involuntária um mesmo domicílio) é preponderante no déficit habitacional nas cidades, principalmente em áreas de cortiços, mas pouco significativa no ambiente rural. O inverso ocorre com a precariedade construtiva (definida principalmente pelo uso de materiais rústicos como taipa e cobertura de palha), que tem presença mais relevante no déficit no campo do que nas cidades. $\mathrm{O}$ terceiro fator, que é o adensamento domiciliar (em que há mais de 3 pessoas por qualquer dependência que seja usada como dormitório) é o de menor participação tanto em meio rural quanto urbano, o que se deve provavelmente à queda das taxas de natalidade no Brasil, isto é, à diminuição de tamanho das famílias mais do que ao aumento de tamanho dos domicílios.

Diferentemente dos três fatores acima, a metodologia da Fundação João Pinheiro aplica unicamente em meio urbano o quarto fator que determina a contagem de um domicílio como déficit habitacional: o "ônus excessivo de aluguel", em que a locação do domicílio consome mais de 30\% da renda familiar média mensal. Mais ainda, esse fator também só é considerado como fator de déficit quando a renda domiciliar é igual ou inferior a 3 salários mínimos, pois uma despesa elevada com aluguel que onera uma renda domiciliar igualmente elevada não compromete obrigatoriamente outras necessidades vitais de uma família.

Pois é este quarto fator, exclusivamente urbano e de baixa renda, o único cuja contagem entre os domicílios brasileiros se elevou de forma consistente desde 2007, tanto em termos absolutos quanto relativos, como se vê abaixo:

Gráfico 1. PNDA - Fatores do déficit habitacional no Brasil - 2007/2012

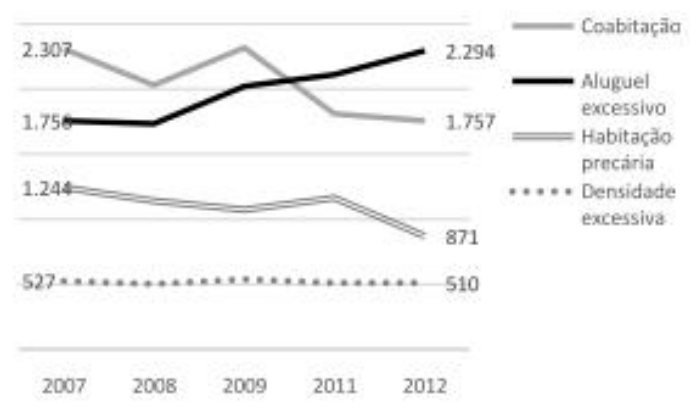

Fonte: elaboração própria a partir de Lima Neto, Furtado e Krause (2013, p. 6).

Obs.: Valores em milhares de domicílios. Como um domicílio pode apresentar mais de um fator de déficit, as somas são superiores às quantidades apresentadas na Tabela 4. 
A informação a extrair do Gráfico 1 é que as famílias de baixa renda nas cidades estão ingressando cada vez mais no déficit habitacional não por uma condição construtiva ou espacial do domicílio (a rusticidade dos materiais, o compartilhamento da moradia ou dos dormitórios), mas por uma condição eminentemente social do domicílio - o aluguel - cujo valor é regulado, em última instância, pela abstração do mercado de localizações urbanas.

De fato, um valor de aluguel que compromete as despesas básicas de uma família além da habitação é uma condição integralmente urbana, que não faz sentido ser levantada em meio rural, pois ele mede uma disputa por localização como estratégia de vida nas cidades: paga-se mais aluguel, até mesmo por uma moradia mais precária ou em coabitação, porque este é o preço da proximidade com equipamentos coletivos ou ofertas de emprego e também é o preço da distância que uma família pobre tenta manter em relação a áreas impróprias para habitação, seja no sentido geotécnico do termo ou outros ainda mais profundos, como a carência de dinamismo econômico e a exposição à violência urbana.

É uma limitação inevitável dos levantamentos estatísticos que, em tais espaços urbanos degradados e violentos, não contem como parte do déficit habitacional uma família que vive isolada numa moradia autoconstruída, dentro da qual seus membros podem dormir em pares pelas dependências erguidas com uma mínima estrutura de concreto armado com fechamentos cerâmicos tipo "bloco baiano", insumos da pobreza mas que não são "rústicos" como palha ou taipa. Quando a recusa de uma família de baixa renda em viver nessa condição periférica acarreta um "ônus excessivo do aluguel", ao menos um subproduto dessa segregação urbana aparece nas estimativas de demanda de moradia ${ }^{11}$.

Se é o valor dos aluguéis que está impedindo a queda do déficit habitacional entre a população de baixa renda, então que papel nele pode desempenhar as metas físicas do programa MCMV? Embora possa aumentar em parte a oferta de imóveis para aluguel (contrariando regras de arrendamento da unidade habitacional da Caixa Econômica Federal), a construção das novas moradias pelo programa implica muito mais um aumento de demanda por terra urbana que, em última instância, sustenta a dinâmica imobiliária recente nas grandes e médias cidades brasileiras, de incessantes elevações de valor para compra e também aluguel de moradia.

\footnotetext{
${ }^{11}$ Segundo o presidente nacional do Instituto de Arquitetos do Brasil, Sérgio Magalhães, a elevação da quantidade de domicílios fora do déficit habitacional não implica por si mesmo numa elevação de qualidade urbanística no Brasil: "o MCMV é um esforço importante, mas é mais do mesmo. Atingindo as metas, construirá 3,4 milhões de moradias em 8 anos, enquanto no período o país terá construído 12 milhões. Como? Tal como antes, na dificuldade, na precariedade, na irregularidade" (MAGALHÃES, 2013, p. 21).
} 
A associação entre o ônus excessivo do aluguel e o período de alta de preços no mercado imobiliário coincidente com a vigência do programa MCMV é uma hipótese inevitável para os autores do Nota Técnica $\mathrm{n}^{\circ} 5$ do IPEA: "O aumento do gasto das famílias pode ser decorrente de acréscimos nos valores de aluguel, em alguma medida, atrelados à valorização imobiliária pela passam as cidades brasileiras no período estudado" (LIMA NETO; FURTADO; KRAUSE, 2013, p. 12).

Há menos hesitação do ponto de vista do movimento de moradia de São Paulo. Segundo Guilherme Boulos, dirigente do Movimento dos Trabalhadores Sem-Teto (MTST), "O valor dos imóveis subiu mais de cinco vezes e o dos aluguéis duas vezes e meia acima da inflação" entre 2009 e 2013:

\footnotetext{
O mercado passou a capitalizar regiões antes periféricas. É o caso do Campo Limpo, distrito com maior concentração d favelas da capital de São Paulo, em que o valor do metro quadrado dobrou desde 2008. O mesmo ocorreu em Itaquera, na zona leste. A consequência é que milhares de famílias que viviam nessas regiões não conseguem mais arcar com o valor do aluguel. (BOULOS, 2013, p. A3).
}

A alta dos aluguéis é o preço final de as sucessivas metas de construção do programa MCMV estarem desvinculadas de uma política habitacional abrangente e controlada por forças sociais outras que o mercado da construção e o mercado imobiliário. As respostas que o PlanHab poderia oferecer para o controle do valor da localização urbana não podem ser oferecidas isoladamente por um programa de provisão habitacional, mesmo um "programa-plano" como o MCMV. Dessa forma, o efeito de suas metas físicas sobre o déficit habitacional brasileiro se limita a um único ponto: concentrar e isolar seu núcleo de pobreza numa segregação urbana que, esta, permanece intocada.

\section{Conclusão: um programa habitacional à prova de crises de superprodução}

Ao menos isso as metas do programa MCMV asseguram ao mercado da construção habitacional: elas não vão gerar uma crise de superprodução, um risco das expansões econômicas que é mais perigoso para o mercado da construção do que a existência de déficits habitacionais.

A rigor, uma crise habitacional se torna uma crise do capital da construção civil apenas quando há ciclos de superprodução. Manter um regime de escassez por habitações, isto é, manter elevada sua demanda junto a um mercado consumidor, é o objetivo mais amplo dos agentes imobiliários que produzem e comercializam residências. Quando o estoque habitacional de um país ou 
mesmo de uma região é elevado, esse objetivo se converte na ampliação da capacidade de endividamento das famílias, ampliação que está na base de todas as crises de superprodução na construção civil. Acontece nesses momentos uma "superprodução de financiamentos", para usar a expressão de Peter Marcuse, um fenômeno que ficou evidente no colapso do sistema hipotecário americano em setembro de 2008 (MARCUSE, 2009). Poucos meses após a internacionalização desse colapso, o déficit habitacional brasileiro, que antes foi estudado como uma crise social, se torna, através do programa MCMV, uma solução para transferir recursos públicos para empresas privadas e mobilizar o capital da construção civil brasileira em tempos de crise financeira mundial.

Para as faixas de renda médias, o programa MCMV de fato promove uma ampliação da quantidade de consumidores pelas modalidades "Faixa 2" e "Faixa 3", em que recursos do Fundo de Garantia por Tempo de Serviço (FGTS) são utilizados para subvencionar o comprador do imóvel. Este tem direito ao seguro das mensalidades pelo Fundo Garantidor da Habitação Popular (FGHab) e, dependendo do perfil de renda, a juros menores e isenção de taxas cartoriais, o que aumenta seu acesso ao mercado residencial formal.

No entanto, para os domicílios de baixa ou nenhuma renda, que compõem o centro e as margens do déficit habitacional brasileiro, o subsídio oferecido pelo MCMV não amplia o mercado consumidor de habitação, pois está vinculado ao arrendamento de uma unidade habitacional produzida unicamente com esse propósito e que não amplia a capacidade de endividamento das famílias junto ao mercado imobiliário. Essas famílias se tornam antes uma demanda fechada, oferecida à construção civil formal através dos cadastros sociais das prefeituras municipais. O Fundo de Arrendamento Residencial fornece, portanto, um subsídio que dá às construtoras acesso às famílias de baixa renda, e não o contrário.

No programa MCMV, a produção habitacional é remunerada por fundos públicos, sem os riscos da criação de um mercado consumidor ou de crédito imobiliário. O déficit habitacional, neste caso, assume unicamente a função de legitimação política: assim como o capital precisa de uma população excedente que regule o preço da força de trabalho, a condução política do programa MCMV precisa de uma população excedente que legitime como um programa habitacional o que na realidade é uma política de desenvolvimento econômica dedicada à ampliação da capacidade produtiva das empresas de construção habitacional ${ }^{12}$.

\footnotetext{
${ }^{12} \mathrm{O}$ material editado neste artigo é em sua maior parte oriundo de pesquisa de doutorado concluída em junho de 2014 na Faculdade de Arquitetura e Urbanismo da Universidade de São Paulo (FAUUSP), sob o título "Trabalho e tecnologia no programa MCMV". O escopo total da tese é relacionar as insuficiências do programa MCMV à própria transformação produtiva realizada em seus empreendimentos para baixa renda.
} 
BARAVELLI, José Eduardo. Subsídio e déficit habitacional no Programa MCMV.

\section{Referências}

ARANTES, Pedro; FIX, Mariana. Como o governo Lula pretende resolver o problema da habitação. Correio da Cidadania, São Paulo, 30 jul. 2009. Disponível em: http://www.correiocidadania.com.br/index.php?option $=$ com content $\&$ task $=$ view $\&$ id $=3580 \&$ Itemid $=79$ Acesso em: 24 jun. 2015.

BONDUKI, Nabil. Do projeto Moradia ao programa Minha Casa Minha Vida. Teoria e Debate, São Paulo, n. 82, p. 8-14, 2009.

BOULOS, Guilherme. Quando o discurso não convence. Folha de S. Paulo, São Paulo, p. A3, 27 dez. 2013.

BRASIL. Ministério das Cidades. Plano Nacional de Habitação - PlanHab. Brasília, DF, 2009.

BRUNA, Paulo. Arquitetura, industrialização e desenvolvimento. São Paulo: Perspectiva, 1976.

CARDOSO, Adauto. (Org.). O Programa Minha Casa Minha Vida e seus efeitos territoriais. Rio de Janeiro: Letra Capital, 2013.

DAMÉ, Luiza. Meta do MCMV2 sobe para 2,4 milhões de casas. $O$ Globo, Rio de Janeiro, p. 22, 12 abr. 2012.

FERREIRA, João Setti. (Org.). Produzir casas ou construir cidades? São Paulo: LabHab/ Fupam, 2012.

FUNDAÇÃO JOÃO PINHEIRO - FJP. Déficit habitacional no Brasil 2008. Brasília, DF: Ministério das Cidades, 2011.

KRAUSE, Cleandro; BALBIM, Renato; LIMA NETO, Vicente. Minha Casa Minha Vida, nosso crescimento. Rio de Janeiro: IPEA, 2013. (Texto para Discussão, 1853).

LIMA NETO, Vicente; FURTADO, Bernardo; KRAUSE, Cleandro. Estimativas do déficit habitacional brasileiro (PNAD 2007-2012). Brasília, DF: IPEA, 2013. (Nota Técnica, 5).

MAGALHÃES, Sérgio. Minha casa no país do carro zero. $O$ Globo, Rio de Janeiro, p. 21, 27 abr. 2013.

MARCUSE, Peter. A Critical Approach to the Subprime Mortgage Crisis in the United States. City \& Community, Washington, v. 8, n. 3, p. 351-356, 2009.

MARICATO, Ermínia. O "Minha Casa" é um avanço, mas segregação urbana fica intocada. Carta Maior, São Paulo, 27 maio 2009. Disponível em: http://cartamaior.com.br/?/Editoria/ Politica/O-Minha-Casa-e-um-avanco-mas-segregacao-urbana-fica-intocada/4/15160 Acesso em: 24 jun. 2015.

MARICATO, Ermínia. O impasse da política urbana no Brasil. São Paulo: Vozes, 2011.

NASCIMENTO, Denise; TOSTES, Simone. Programa Minha Casa Minha Vida. Arquitextos, 130, 2011. Disponível em: http://www.vitruvius.com.br/revistas/read/arquitextos/12.133/3936 Acesso em: 24 jun. 2015. 
RODRIGUES, Evaniza. A estratégia fundiária dos movimentos populares na produção autogestionária da moradia. 2013. 233 f. Dissertação (Mestrado em Arquitetura e Urbanismo) Faculdade de Arquitetura e Urbanismo, Universidade de São Paulo, São Paulo, 2013.

ROLNIK, Raquel; NAKANO, Kazuo. As armadilhas do pacote habitacional. Le Monde Diplomatique Brasil, São Paulo, n. 20, 09 mar. 2009. Disponível em: http://www.diplomatique.org. br/artigo.php?id=461 Acesso em: 24 jun. 2015.

SINGER, André. Os sentidos do lulismo. São Paulo: Cia das Letras, 2013.

Submissão em: 10/02/2015

Revisão em: 19/05/2015

Aceite em: 31/05/2015

José Eduardo Baravelli é arquiteto, mestre e doutor pela FAU/USP. Professor no Centro Universitário FIAM-FAAM. Endereço: FIAM-FAAM - Arquitetura e Urbanismo. Rua Agostinho Rodrigues Filho, 201. Vila Mariana - São Paulo/SP, Brasil. E-mail: jbaravelli@gmail.com 